\title{
The road to success in international rowing
}

\author{
Richard G.Mc.B. Budgett MA, MRCGP \\ Olympic Gold Medallist, Coxed Fours, Los Angeles, 1984
}

British Olympic Medical Centre, Northwick Park Hospital, Harrow

The ambition of most young British oarsmen is to row in their 1st Club or University VIII, and only then do they start to dream about selection to row for Britain let alone winning Olympic medals. However, the road to international success is fraught with pitfalls, deadends and broken hearts!

The image of rowers as big men is justified especially since the introduction of long slides and the modern style of rowing two decades ago ${ }^{1,2}$. Long legs are efficient levers, and top rowers seem to get taller every year, so that $6 \mathrm{ft}$ 6in is no longer exceptional and $6 \mathrm{ft}$ is small, necessitating enormous strength to compensate. In order to succeed, the oarsman must be gifted with a very large absolute $\mathrm{Vo}_{2}$ max of around 6 litres/min or more, as well as power and strength.

Assuming an athlete has the genetic attributes, there are many other pitfalls which can stunt the blossoming of talent. Like most Olympic sports, rowing takes up a huge amount of time, and so international aspirants will have to give up or delay their careers. For example, rowing medics are either students, or delay starting work as I did. One surgical houseman, a world championship medallist, failed to be selected for the Olympics after trying to train during a sixmonth house-job. Students risk failing their exams, and like everyone else are constantly short of money, despite the sports sponsorship bonanza which is only just beginning to benefit the very top rowers.

With the advent of the squad system, oarsmen must be within reach of London, and relationships suffer as mornings, evenings and weekends are taken up. Even with this commitment, only half of those registered for international selection are successful. It is amazing that so many international oarsmen become hopelessly addicted and carry on year after year.

The mental attitude needed for rowing is much talked about in bars, but out on the water it's a matter of winning. It's winning that drives rowers on, and because it's a non-contact sport, all aggression is channelled into pulling harder on the oar. It doesn't matter if individuals in a crew hate each other (which is fortunately unusual) as long as there is mutual respect and they trust each other's commitment to

(C) 1989 Butterworth \& Co (Publishers) Ltd 0306-3674/89/010049-02 \$03.00 win. The coach can help to mould the crew together into a single winning unit, but if that respect and trust breaks down, rowing can become an intra-boat contact sport and the crew will loose!

Even assuming an oarsman is lucky enough to have the right physiology, morphology, and mental attitude and is prepared to make all the necessary sacrifices, he may still fail. Injury, illness or faulty training can shatter his dreams.

In the 1960s and early 1970s the Eastern Block, particularly East Germany, dominated international rowing due to their superior selection and training regimes. They were simply fitter and stronger than all but the most exceptionally gifted Western oarsmen. Now a more professional approach has been adopted in the West, with similar maximum training. This means that the deciding factors in winning medals are the selection of talent and its development, the perfection of technique, and the avoidance of injury and illness.

International oarsmen injured for more than 30 days in a season are very unlikely to be selected. The injury rate during land training is about ten times that during rowing, but in over 90 per cent of oarsmen registered for international selection, injuries are minor, and do not affect their selection or medal chances, the most common being soft tissue injuries to the back, and tenosynovitis of the wrist extensors ${ }^{3}$. However, I know from personal experience that even a minor soft tissue injury can seem devastating when it interrupts training. The anxiety and loss of confidence can be disabling, until a good result restores that fully committed will to win.

Training regimes are the subject of many arm-chair disputes, and proponents will point to great successes, including Olympic medals won, with their particular programme. The British national coach has cut land training to an absolute minimum, with no heavy weights and endless hours spent on the water. At the other extreme, some Australian international coaches carry on with heavy weights right through the racing season to build up and maintain maximum muscle power. Medal winning Scandinavian crews use cross country skiing through their frozen winters. However, all regimes do end up spending most of the time rowing either on the water or an ergometer. Muscles will respond to training in a remarkably specific way ${ }^{4,5}$, 
and it is this sports specific training that develops genetic talent into Olympic gold medals.

Nevertheless, there is a role for land training as long as the benefits are carefully weighed against the injury risks. It provides a fresh stimulus, and is convenient during the cold dark winter months, helping to build up muscle bulk and strength, and increase aerobic fitness. There is evidence that weight training circuits will actually help prevent injuries ${ }^{6}$ by increasing strength and flexibility and by training antagonist muscles, and contralateral muscles in one-sided oarsmen. In common with many oarsmen, I hated land training, and won my first international medal having done no heavy weight training at all. But in retrospect, there is no doubt that it did help convert a bronze to a gold medal over the next three years.

The overall volume and intensity of training has to be planned to stress all members of a crew enough for them to reach their maximum potential, but at the same time allow them to recover. This is a delicate balance. Fortunately oarsmen rarely seem to become overtrained probably because they are protected in a crew where the volume and intensity of training is controlled and they are forced to take adequate rest. However, with the increasingly professional approach needed, and growth of individual training in single sculls there is the risk of highly motivated oarsmen failing to give themselves time to recover. This leads to the downward spiral of deteriorating performance, and increased training load in a misguided attempt to regain performance, until the athlete is persuaded or forced to rest ${ }^{7,8}$.

In conclusion, the road to success in international rowing is long and uncertain. Only those who are crazy enough to enjoy rowing, and hungry enough to win, will try, and only some of these will succeed.

\section{References}

1 Stallard, M.C. Backache in oarsmen Br J Sports Med 1980, 14, 105-108

2 Green Eaw, Annotation: Comfort to contortion: the last ten years of rowing $B r J$ Sports Med 1980, 14, 109

3 Budgett, R. and Fuller G. Illness and injury in international oarsmen Clin Sports Med (in press)

4 Rutherford, O.M. Muscular coordination and strength training: Implications for injury rehabilitation Sports Medicine 1988, 5, 196-202

5 Rutherford, O.M. The role of learning and coordination in strength training Eur J Appl Physiol 1986, 55, 100-105

6 Marcinik, L. et al. A comparison of sprain and strain injury rates during aerobic/callisthenic and aerobic/circuit weight training programs Military Medicine 1987, 152, (5), 252

7 Crampton J. and Fox J. Regeneration vs burnout: Prevention is better than cure! Sports Coach 1987, April June, 7-11

8 Morgan, W. et al. Psychological monitoring of overtraining and staleness Brit J Sports Med 1987, 21(3), 107-114 